\title{
Editorial: Quality and Inequality in Regional and Urban Systems
}

\author{
Karima Kourtit ${ }^{1}$, Peter Nijkamp ${ }^{2}$, Roger Stough ${ }^{3}$ \\ ${ }^{1}$ KTH Royal Institute of Technology, Stockholm, Sweden; Adam Mickiewicz University, Poznan, Poland \\ ${ }^{2}$ KTH Royal Institute of Technology, Stockholm, Sweden; Tinbergen Institute, Amsterdam, The Nether- \\ lands; Adam Mickiewicz University, Poznan, Poland \\ ${ }^{3}$ George Mason University, Fairfax VA, USA
}

Received: 2 September 2018/Accepted: 17 September 2018

\begin{abstract}
In the aftermath of both ongoing globalisation (with both widening and deepening effects on countries, regions and cities) and structural changes resulting from the 2008 economic recession, regions and cities in our world are confronted with a different arena of players, performances and institutions. The challenges are formidable and numerous. Many regions and cities seem to resort to their indigenous strength, without much regard to other players in the field. This has enormous consequences for the competitive behaviour and profile of regional and urban actors but has at the same time deep impacts on the distribution of wealth, income and employment over and within countries, regions and cities. There is indeed much evidence that disparities among regions and in cities are increasing in this new force field.

This special issue of REGION makes a solid scientific attempt (i) to map out the spatial consequences of recent transitions in growth trajectories of countries or regions, and (ii) to trace policy strategies and design effective policy information, to cope adequately with these new challenges. The present special issue does so by highlighting the new force field of regional and urban dynamics from three angles in the context of spatial quality and inequality. These will be briefly sketched below.
\end{abstract}

\section{Introduction}

Economies have always had to adjust to the impact of external and internal disequilibrating forces. So, there is nothing new, in general, that the disequilibrating impact that globalization and technological transformation are creating in the functioning of national and regional economic systems. However, it is the speed that these changes are occurring and thus tossing the operation of economic systems into turmoil that is creating new challenges out of the ordinary continuous adjustment and adaptation. When globalization is coupled with information, communication and new telecommunications (ICT) technological change, then the speed of change is accelerated. This speed is not only fast but also continuous, thus resulting in a need to constantly anticipate new developments and at the same time adjust to the newest stressors. The papers for this special edition are presented as a package of some of the consequences of high speed, continuous change and adaption in the face of these changes.

This special edition is presented in three parts. The first considers the role of knowledge and creativity, on the one hand, as drivers of change and, on the other, as factors in 
the continuous adjustment process. New knowledge in the age of ICT and globalization driven change help to create new ideas and transform them through innovation at an ever-increasing rate into viable and productivity enhanced organizations in both the public and private economic milieu. While serving as major sources of economic growth, knowledge, ICT and globalization also contribute to the adjustment process via new economic planning, policy and management techniques.

\section{Part A: Creativity and Knowledge as Enabling Factors of Spatial Economic Growth}

In the first part of this edition, four papers explore the role of these factors in driving and adapting to change. The first paper examines the concept of effective economic clusters and their role in producing economic growth and dynamic adjustment. The second considers the evolution of the craft beer industry as an endogenous growth model or force in the context of regional growth dynamics. Next, there is a paper that advocates the role that art and culture play in reconfiguring the built environment and an impact that this may have on regeneration of society and economy in urban settings. Finally, the fourth paper provides the analysis of how a local community is becoming a R\&D and science driven urban economic center, but without a university. These four papers follow in Part A under the heading of creativity and knowledge as enabling factors of spatial economic growth.

\section{Kourtit, K., P. Njkamp and S. Suzuki (2017) "Effective Clusters as Territorial Performance Engines in a Regional Development Strat- egy - A Triple Layer DEA Assessment of the Aviation Valley in Poland", REGION, 4(3), 39-63.}

This paper introduces the concept of effective clusters which are viewed as economictechnology clusters possessing spatial economic synergy, local and region concentration of industry and supporting territorial capital. It is argued that these clusters are center pieces of sustainable territorial performance strategies. A case study focused on one of the most vibrant high technology clusters in Poland, the Dolina Lotnicza Aviation and Aerospace cluster located in the Podkarpackie Region in Southwest Poland. The analysis is multi-level with a benchmark analysis of 25 counties, a comparison of performance of the Dolina Lotnicza cluster with the benchmark analysis, and an efficiency analysis using a super efficiency DEA model of the 16 Polish administrative regions. The case study is used to evaluate the argument that effective clusters are core territorial performance enhancing engines. The findings support the effective cluster concept.

\section{Reid, N. and J.D. Catrell (2017) "Creativity, Community and Growth: A Social Geography of Craft Beer", REGION 4(1), 31-49.}

This paper uses the craft beer industry as a vehicle to examine the non-economic growth drivers in emerging industries. Two case studies serve to better understand how the values of entrepreneurs and local firms fit into the way work, place and creativity contribute to the production of growth. Also, the meaning of creativity relative to the craft beer industry is explored and examined. Finally, the results produce a hypothesis that views creativity as a significant factor in niche and emerging industries.

Onesti, A. (2017) "Built Environment, Creativity and Social Art: Recovery of Public Space as Engine of Human Development", REGION, 4(3), 87-118.

The thesis of this paper is that the recovery of public space configured by art and culture and shared with the local community with an inclusive approach, contributes to regenerate creativity, restructuring the relationships among people, communities and landscape. The author argues that this lays the foundation for a creative and regenerative approach. The paper is erected on interpretive analysis and has three major objectives. First is to produce empirical evidence on the relationships among art, heritage and community. 
Second, the aim is to develop a methodology for soliciting, integrating and supporting the regeneration of relationships in the town of Torre Annunziata, a case study. And third, the aim is to show the potential of new planning tools.

\section{Snickars, F.V. and U. Karlsson (2017) "Research Infrastructure, Networks of Science and Regional Development - The Case of Os- karshamm", REGION, 4(3), 119-131.}

This paper examines how the Oskarshamm region in Sweden appears to have become an R\&D center with a wide-ranging scientific network without a university. The Oskarshamm region became the locus along with other places such as Lund, Hamburg and Kiruna of analyses in search of a final location for the internment of nuclear waste. These studies concluded that Oskarshamm was one of the most likely disposal sites. Infrastructure and social network analysis were used to estimate the resulting changes in scientific and infrastructure capacity of Oskarshamm. Over time the analysis of the Oskarshamm site built a strong base of scientific human capital and cooperation between scientists and industry there. The paper focuses on the accumulation of scientific know-how and industry/science cooperation in Oskarshamm as a development that enhanced its technological and scientific infrastructure and thus its regional development capacity.

\section{Part B: Structure and Change in Regional Dynamics}

Part B has four papers that relate to economic and spatial structure and their relationship to regional dynamics and vice versa. The first paper examines the correlates of new firm formation in the New England Region of the U.S. and concludes that some of these correlates support prevailing theory and beliefs, but some provide evidence of contradicting conclusions. A second paper examines the relationship between urban concentration and the ownership of natural resources in countries and concludes that the spatial distribution of ownership of resources positively influences urban population densities. The third paper examines the impact of the 2008 global recession on capital stocks in the autonomic regions of Spain and finds that yields of the post 2008 remaining capital are so low in some regions that regional growth has declined significantly. Finally, the last paper in Part B considers a set of indicators for evaluating the role of the cultural urban landscape's contribution to sustainable development and thus contributes to the debate on the future of sustainable development policies and programs.

\section{Parjuli, J. and K. Haynes (2017) "Panel Data Models of New Firm Formation in New England", REGION, 4(3), 65-76.}

This study examines the determinants of new firm formation at the county level (19992009) in New England, USA. A panel data spatial econometric analysis finds that human capital and population density are positively associated with single unit firm births in both counties and their neighboring counties. Population growth rate also has a significant positive effect on new firm formation with most occurring in spillovers flowing from a growing county to its neighbors. Firm births are negatively affected by the ratio of large/small firms and unemployment rate both within counties and its neighbors. However, no significant impact is found from levels of local financial capital and personal income growth. The paper is of interest, because it tests and challenges some prevailing conclusions about the determinants of new firm formation.

\section{Denthino, J.P. (2017) "Urban Concentration and Spatial Alloca- tion of Rents from Natural Resources: Zipf's Curve Approach", REGION, 4(3), 77-86.}

Concern in this paper is with the hypothesis that the dependence level of a country on natural resources may positively influence the level of urban concentration. Analysis of a group of countries using a Zipf curve approach shows that countries with a higher level of urban concentration have higher levels of income coming from natural resources and education expenditures, while public expenditures on health and foreign direct 
investment (FDI) contribute to spatial redistribution. The paper concludes that the spatial distribution of property rights over resources and related rents influence urban concentration densities.

\author{
Marquez, M.A., J. Ramajo and G.J.D. Hewings (2017) "Regional \\ Public Stock Reductions in Spain: estimations from a Multiregional \\ Spatial Vector Autoregressive Model", REGION 4(1), 129-146.
}

Following the 2008 global recession, public investment in Spain fell, so severely in some regions that they have not been able to replenish depreciated capital. This study models the interdependencies among the Autonomic Regions of Spain using a multiregional specification. The results show that global decreases in public investment have a major and homogeneous effect on the output of all regions. However, regions vary in terms of their public capital stock responses.

\title{
Nocca, F. and F.G. Girard (2018) "Toward an Integrated Evalua- tion Approach for Cultural Landscape Conservation/Regeneration", REGION, 5(1), 33-51.
}

This paper observes and describes the international debate focused on the need for a new paradigm for defining sustainable development policies and programs. Further, the debate has moved the concept of development toward a more futuristic and cultural perspective and is expected to add a focus on adopting a role for cultural heritage in the new paradigm. The paper first discusses potential indicators that could be used to evaluate the ability of the cultural urban landscape's contribution to sustainable development. A multi-dimensional approach for empirical analysis and for measuring the effects of the cultural urban landscape on sustainable development in general and more specifically on its conservation and regeneration is proposed at the end of the paper.

\section{Part C: Spatial Mobility and Economic Disparity Effects}

Part $\mathrm{C}$ has three papers that focus on aspects of spatial mobility and economic/income disparity impacts in 21st century economies. The first two papers focus on competitiveness and sustainability of the tourism industry in Spain and the NUTS 2 regions of the European Union, respectively. The last paper examines wage and employment spatial mismatch developments in the metropolitan areas in Brazil. The first paper examines competitiveness performance of the autonomous regions of Spain and concludes that poorer performing regions should consider changes in how their destination businesses operate in such areas, for example, in marketing and enhancing service quality. Next, a second study on a space/time analysis of NUTS 2 regions concludes that dynamics in the tourism industry often have positive competitiveness effects and tend to ameliorate the negative impacts of interregional competition. The final paper of Part $\mathrm{C}$ examines the spatial mismatch problem and hypothesis for Brazil. The analysis finds that there is little evidence supporting this hypothesis when the measure is job opportunities. However, when the metric used for the analysis is wages, they find that the mismatch problem is stronger in large metropolitan regions and for low income workers.

\section{Martin, J.C., C. Mendoza and C. Roman (2017) "Regional Spanish Tourism Competitiveness", REGION, 4(3), 153-173.}

This paper relates an analysis of the regional tourist competitiveness performance of the autonomous regions of Spain using superior DEA Efficiency modeling to produce a performance ranking of the regions' efficiency (that is, their competitiveness). Madrid and La Rioja regions have a high level of competitiveness, while the more interior regions of Spain are less competitive. The study concludes that the lagging regions should examine practices of their destination management organizations and take corrective action.

Romano, J., J. Guerreio and P. Rodrigues (2017) "Territory and Sustainable Tourism Development: Space Time Analysis on European Regions", REGION, 4 (3), 1-17. 
This paper examines the role of resource and culture assets in tourism supply and sustainability. Using advanced spatial econometric analysis of data for the European NUTS 2 regions, it is found that natural resources do not have an expected positive effect on tourism competitiveness. Further, regions with abundant natural resources often have developed unsustainable mass forms of tourism with low value added and with little benefit for host communities. The analysis also supports a conclusion that spatial autocorrelation exists and that spillovers from tourism dynamics tend to have a positive effect on tourism competitiveness and thus to offset negative effects of competition among regions.

\section{Barufi, A.M. and E.A. Haddad (2017) "Spatial Mismatch: Wages and Employment in Metropolitan Areas of Brazil", REGION, 4(3), 175-200.}

This paper examines the hypothesis that a lack of accessibility to job opportunities may affect an individual's prospects in the labor market, especially for low-skilled workers. This is more commonly called the spatial mismatch hypothesis. Analysis finds that there is little evidence that this hypothesis holds for residents of metropolitan areas of Brazil. However, there is support for the hypothesis, when the labor market measure used is wages. Further, when wages are used, the impact is higher for large metropolitan regions and for low-skilled workers.

All in all, we may conclude that a thorough analysis of spatial quality and inequality in a geographically heterogeneous world calls for advanced statistical and econometric techniques. Such a diversified toolbox is a sine qua non for a better understanding of spatial complexities in a dynamic and open world economy.

cc) (7) (8) (C) 2018 by the authors. Licensee: REGION - The Journal of ERSA, European Regional Science Association, Louvain-la-Neuve, Belgium. This article is distributed under the terms and conditions of the Creative Commons Attribution, Non-Commercial (CC BY NC) license (http://creativecommons.org/licenses/by-nc/4.0/). 